\title{
الأخطاء في ترجمة اللغة الإندونيسية إلى اللغة العربية
}

\author{
(دراسة حالة عن نتائج ترجمات طلاب قسم التعليم اللغة العربية جامعة دار السلام \\ الإسلامية)

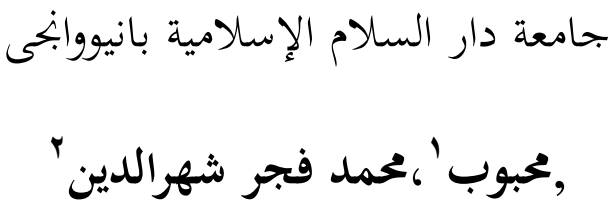

‘Email: muhfajarsy@gmail.com, mahbubnawawi@gmail.com

\begin{abstract}
Abstrak
Penelitian ini bertujuan untuk mengetahui dan mendeskripsikan kesalahankesalahan dan penyebab-penyebabnya yang terjadi pada hasil penerjemahan yang dilakukan oleh mahasiswa Pendidikan Bahasa Arab angkatan tahun 2016. Data penelitian ini diperoleh dari hasil penerjemahan para mahasiswa yang diambil menggunakan teknik tes tulis. Setelah hasil penerjemahan diperoleh, selanjutnya dilakukan identifikasi kesalahan, klasifikasi kesalahan dan rekontruksi kesalahan. Bentuk-bentuk kesalahan yang terjadi pada hasil terjemah para mahasiswa adalah kesalahan pemilihan kata, kesalahan penghilangan kata, kesalahan penambahan kata, kesalahan kaidah, dan kesalahan bentuk kata. Adapun penyebab kesalahan, terdapat dua hal yang mendasari terjadinya kesalahan yang ditemukan, yaitu transfer interlingual dan transfer intralingual.
\end{abstract}

Kata Kunci: Analisis Kesalahan, Bahasa Arab, Pendidikan Bahasa Arab, Institut Agama Islam Darussalam

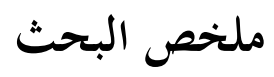

$$
\begin{aligned}
& \text { وكان إجراء هذا البحث لمناقشة الأخطاء الموجودة والعوامل المسببة في نتائج ترجمة طلاب } \\
& \text { قسم تعليم اللغة العربية لعام } 7 \text { • r جامعة دار السلام الإسلامية بلوك أكونج } \\
& \text { بانيووانكى. وتم الحصول على بيانات هذه الدراسة من نتائج توجمة الطلاب النين تم } \\
& \text { أخحلهم باستخلدام تقنيات الاختبار التحريري. بعل الحصول على نتائج الترجمة ، يتم } \\
& \text { تحلديد الخطأ وتصنيف الخطأ وإعادة بناء الخطأ. وأثكال الأخطاء التي تحلدث في ترجمة } \\
& \text { الطلاب هي الأخطاء في اختيار الكلمات ، والأخطاء في حذف الكلمات ، والأخطاء } \\
& \text { في زيادة الكلمات ، والأخطاء في القواعل النحوية ، والأخطاء المورفولوجية. وفيما يتعلق }
\end{aligned}
$$


بأسباب الأخطاء ، هناك شيئان أساسان للأنطاء التي تم العثور عليها ، وهما التحويلات البينية والتحويلات داخل اللسان.

الكلمات المفاتحية : تحليل الأخطاء ، اللغة العربية ، قسم تعليم اللغة العببية ، جامعة

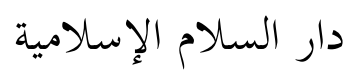

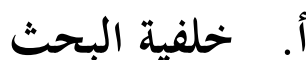

تتطلب ترجمة لغة أن يكون المتزجم قادرًا على نقل الرسالة التي ينقلها متحدث

اللغة المصدر إلى مستمع اللغة المدف (هداية الله ، V| Y : 1). هذا يدل على أن الترجمة لا يككن أن تتم إلا مع قدرة ماهرة. كالقدرة على التحدث باللغة العربية ، التى هي يجب دائمًا تطويرها وتحسينها لأن البشر مطلوب ليكون قادرا على التواصل مع أي شخص في ختتلف جوانب الحياة ، وخاصة في المعلومات والعلوم.

ويعد فهم الأفكار أو الرسائل التي تنقلها الدول الأخرى إحدى مهام الطلاب بشكل عام وخاصة للطلاب الذين يركزون على اللغة. وهذا يرجع إلى العديد من مراجع اللغات الأجنبية. بالإضافة إلى ذلك ، فإن مهمة الطلاب ليست بجرد فهم ، ولكن من المتوقع أيضًا أن يكون الطلاب قادرين على إعطاء أو نقل فكرة إلى دول أخرى بلغتهم. ومع ذلك ، في الواقع توجد أخطاء كثيرة من الأحيان في ترجمة لغة المصدر إلى اللغة المدف. بحيث يصبح تسليم الأفكار من لغة المصدر إلى لغة الهدف غير مناسب ويتغير المعنى. كما يفعل أحد طلاب قسم تعليم اللغة العربية جامعة دار السلام 
الإسلامية في ترجمة كلمة "diskusi" التى يجب أن تكون باللغة العربية هي كلمة "مناقشة" ولكن يترجم الطالب إلى كلمة "منقشة" معناه إعطاء اللون (منور ، 1997 : 190 ـ (). هذا المثال هو خطأ لغوي فادح للغاية لأنه يغير معنى لغة المصدر. ولذلك ، يهتم الباحث بتحليل نتائج ترجمة طلاب قسم تعليم اللغة العربية لعام

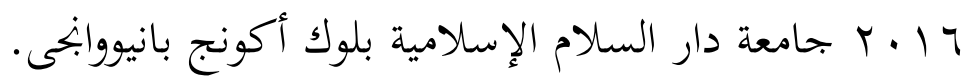

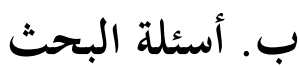

بناءً على الحلفية الموضحة ، هناك نوعان من المشكلة في هذه الدراسة ، وهما: 1. ما هي الأخطاء في نتائج ترجمة النص الإندونيسي إلى اللغة العربية لطلاب قسم تعليم اللغة العربية لعام Y Y T جامعة دار السلام الإسلامية بلوك أكونج

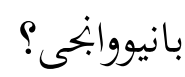
r. ما هي أسباب الأخطاء في نتائج ترجمة النص الإندونيسي إلى اللغة العربية لطلاب قسم تعليم اللغة العربية لعام Y ب ب جامعة دار السلام الإسلامية بلوك أكونج

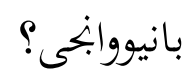

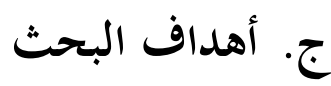
الغرض من هذا البحث هو معرفة إجابات المشكلات المذكورة ، وهي: 
1. وصف أشكال الخطأ في نتائج ترجمة النص الإندونيسي إلى اللغة العربية لطلاب قسم تعليم اللغة العربية لعام Y ب ب جامعة دار السلام الإسلامية بلوك أكونج

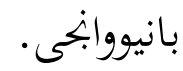
r. وصف أسباب الخطأ في نتائج ترجمة النص الإندونيسي إلى اللغة العربية لطلاب قسم تعليم اللغة العربية لعام Y ب ب جامعة دار السلام الإسلامية بلوك أكونج

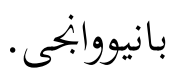

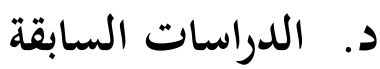

نتائج الأبحاث السابقة حول الترجمة ، تمكن الباحثون من العثور على ثلاث

نتائج

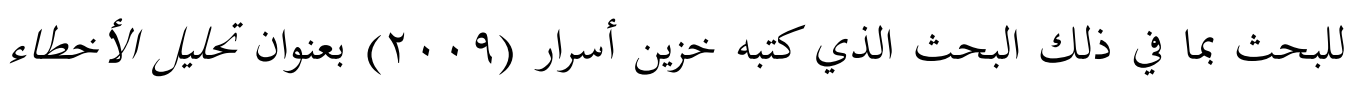
في ترجمة اللغة العربية إلى اللغة الإندونيسية لتلاميذ فصل العاشر في المدرسة العالية الحكومية ونوكرومو يوجياكتًا. ومحور البحث الذي أجراه خزين أسرار هو الأخطاء اللغوية المتعلقة بترجمة النص العربي إلى الإندونيسية. في بحثه ، تم استنتاج أن الأخطاء التي ارتكبها طلاب الصف العاشر في المدرسة العالية واناكراما تم تقسيمها إلى أربعة جوانب ، هي الدلالات ، التشكل ، بناء الجملة وإعادة الهيكلة. 
في هذه الدراسة ، توجد أوجه تشابه في موضوع البحث ، ألا وهي أخطاء الترجمة ، ولكن هناك اختلافات في اللغة التي تمت دراستها. قام الباحث السابق في الدراسة السابقة بمراجعة خطأ ترجمة اللغة العربية إلى اللغة الإندونيسية ، وقد فحص الباحث في هذه الدراسة خطأ ترجمة اللغة الإندونيسية إلى اللغة العربية. بالإضافة إلى ذلك ، هناك أيضًا أشياء مادية مختلفة ، حيث كانت الكائنات المادية في هذه الدراسة طلابًا لقسم تعليم اللغة العربية لعام 1 ـ ب في الجامعة دار السلام الإسلامي بلوكاجونج· نتائج الدراسة التالية هي عمل عتيق رحتك (V V ا (Y) على تحليل الأخطاء في الترجمة مع العنوان تحليل الأخطاء النحوية في توجمة النصوص الإنلدونيسية إلى العببية في البرنامج الخاص لتعليم اللغة العربية بجامعة مولانا مالك إبراهيم الإمالامية الحكومية مالانج. ركزت في بكثها على قواعد النحوية للخطأ التي حدثت في نتائج الترجمة الإندونيسية إلى العربية. ونتائج بحثها هي أن معظم الأخطاء في القواعد النحوية تتعلق بمسألة اسم التفضيل والفعل المضارع والنعت وجمع التكسير والأفعال والمضاف إليه والمجرور والضمير. في الدراسة السابقة ، كان للبحث الذي أجراه عتيق رحتك كائنًا رسميًا مشترًا مع البحث الذي قام به الباحث. ومع ذلك ، هناك اختلافات في البحث السابق ، 
حيث ركزت بحثها على الأخطاء النحوية. بينما يحلل الكاتب الأخطاء في نتائج الترجمة بشكل عام دون التركيز على دراسات لغوية محددة.

$$
\text { هـ الإطار النظري }
$$

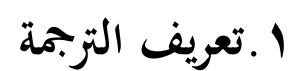

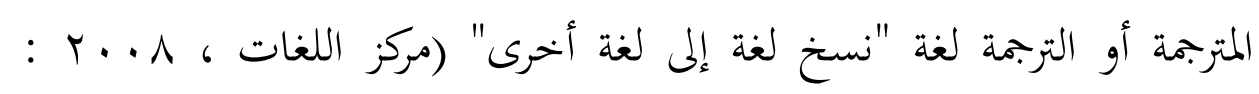

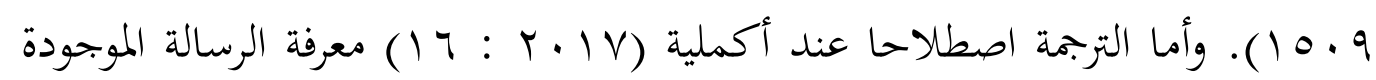
في لغة المصدر عن طريق نقلها إلى اللغة المستهدفة. ووفقًا لنور مفيد وكاسرون ع.س رحمن (V . . F : T) الترجمة هي استبدال المعلومات أو الرسائل أو الأفكار أو الأفكار أو الأفكار من لغات المصدر إلى اللغة الهدف. وعند جيه سي كالفورد (في أسرار ،

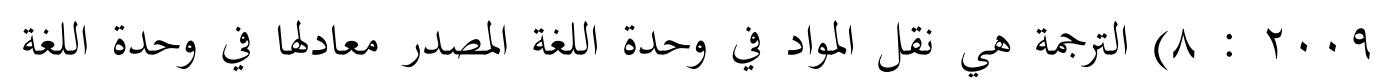
الهدف.

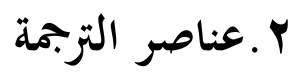

وفقًا للتعريف الموضح ، هناك عدة عناصر في الترجمة مرتبطة دائمًا ، بما في

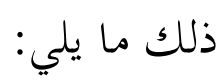

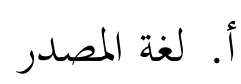
لغة المصدر هي اللغة الأصلية المستخدمة في نقل الرسائل أو المعلومات أو 
الأفكار من قبل الباحث (أسرار ، 9 . . . : 11). ويشير لغة المصدر في هذه الدراسة إلى اللغة الإندونيسية أي اللغة المستخدمة من قبل الباحث لنقل رسالته.

$$
\text { ب. لغة مستهدفة }
$$

اللغة العربية كلغة مستهدفة في هذه الحالة هي أداة للتعبير عن الأفكار الواردة في لغة المصدر ، وهي الإندونيسية. نظرًا لأن اللغة الإندونيسية لها خصائص ميزة ، فإن للغة العبية الخصائص التي تكمن في أنواع الجمل والقواعد اللغوية وهيكل الجمل والمفردات والمصطلحات والتحية والأمثال واللغويات والقواعد النحوية والمورفولوجية

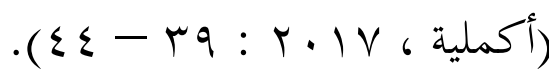

$$
\begin{aligned}
& \text { ج· الرسالة }
\end{aligned}
$$

الرسالة هي جوهر اللغة لأن اللغة كما قالها سورايا تشاباكيا (ع ا ب : Y) هي

أداة تواصل بين البشر ، سواء كانوا أفرادًا أم جماعات أم غير ذلك. وفي التواصل الذي يتم نقله هو رسالة أو معلومات ، بحيث تكون الترجمة عند الترجمة عنصرًا لا يمكن تجاهله.

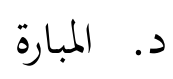

المطابقة في هذه الحالة هي كلمة أو عبارة بلغة أخرى لها معنى ذي معنى أو لها

$$
\text { نفس معنى اللغة المترجمة (مركز اللغات ، م . . ب). }
$$




\section{r.الأخطاء اللغوية}

الأخطاء اللغوية هي انحرافات منتظمة ومتسقة. يختلف تعريف الخطأ (error)

عن مفهوم (mistake). الأخطاء (mistake) ليست انحرافات منهجية ، مثل الأخطاء

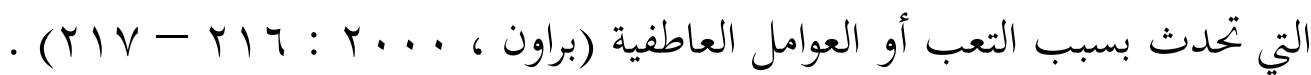

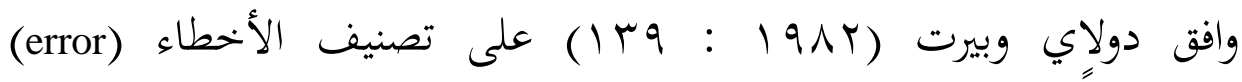

والأخطاء (mistake) ، لكنه لم ينكر أن مصطلح الخطأ (error) يستعمل لجميع أنواع

الأخطاء.

عند مناقشة أخطاء اللغة ، من الضروري التمييز بين ثلاثة أنواع من الانحرافات

اللغوية. تتضمن هذه الأشياء الثلاثة الخطأ (error) والخطأ (mistake) والسقوط

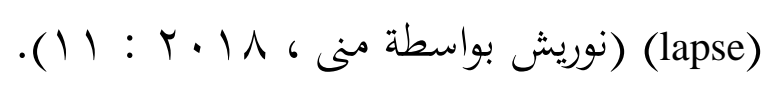

أ. خطأ (error) هو جزء من شكل من أشكال الاخراف اللغوي الناجم عن عدم

إتقان قواعد اللغة الهدف ، ويحدث بشكل منتظم ومستمر.

ب. خطأ (mistake) ، هو انحراف لغوي لا يحدث باستمرار من قبل المتعلمين.

أحيانًا يستخدم المتعلمون عن طريق الخطأ القواعد والنماذج التي يمكنهم

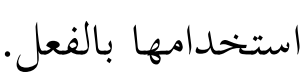


ج. انقطاع اللسان أو انزلاقه ، هو انحراف لغوي يحدث لأي شخص وفي أي وقت بسبب انخفاض ذاكرة المتعلم أو قلة التركيز أو أسباب أخرى.

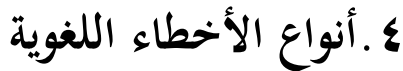

تختلف أخطاء اللغة. ولكن يمكن تجميعها بطرق مختلفة وفقا لمنظورنا. كل وجهة نظر يمكن أن تنتج بجموعة معينة.

المصنف أو التصنيف المستخدم في معرفة الأخطاء اللغوية وفقًا لدولاي

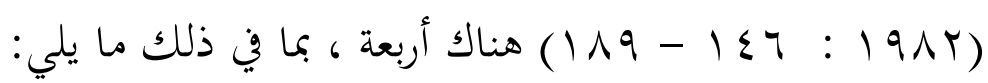

$$
\begin{aligned}
& \text { أ. تصنيف الفئات اللغوية } \\
& \text { ب. تصنيف تكتيكات السطح } \\
& \text { ج. التصنيف المقارن } \\
& \text { د. الآثار التواصلية الضريبية } \\
& \text { ه.تحليل الأخطاء اللغوية }
\end{aligned}
$$

ينص كريستال (بواسطة منى ، 11 ا • ب : 9 1) على أن تحليل أخطاء اللغة هو

أسلوب لتحديد وتصنيف وتفسير الأخطاء اللغوية بشكل منهجي للطلاب الذين هم

في عملية تعلم لغة أجنبية بناءٌ على النظرية أو الإجراء اللغوي.

$$
\text { 7. طريقة تحليل خطأ اللغة }
$$


الأخطاء اللغوية هي شكل من أشكال تبسيط اللغة والخطأ في الفئة اللغوية كما أوضحها هيري جونتور تاريجان في كتابه "تدريس تحليل الأخطاء في اللغة" أن

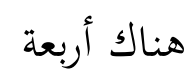

$$
\begin{aligned}
& \text { تصنيفات لأخطاء اللغة. وهي: } \\
& \text { أ. تصنيف الفئات اللغوية } \\
& \text { ب. تصنيف تكتيكات السطح } \\
& \text { ج. التصنيف المقارن } \\
& \text { د. الآثار التواصلية الضريية }
\end{aligned}
$$

يتم إجراء تحليل الأخطاء بشكل عام في الخطوات التالية:

$$
\text { أ. . جمع البيانات من ترجمة طلاب قسم تعليم اللغة العربية. }
$$

ب. تحديد الأخطاء التي لها اهتمام خاص بأهداف محددة أو انخرافات عامة.

$$
\begin{aligned}
& \text { ج. تصنيف أو بتميع بيانات الخطأ. } \\
& \text { د. بيان حول تردد البيانات. } \\
& \text { هـ. تحديد نطاق بيانات الخطأ. } \\
& \text { و. الجهود المبذولة لتصحيح الأخطاء. } \\
& \text { V. عوامل الأخطاء اللغوية. }
\end{aligned}
$$


وفي تدريس اللغة ، تحدث أخطاء اللغة بسبب عدة عوامل أحيانا. ووفقًا لبراون ، فإن الأخطاء اللغوية نابتحة عن أربعة مصادر.

وهي: النقل بين اللغات ، النقل الداخلي ، سياق التعلم واستراتيجية الاتصال

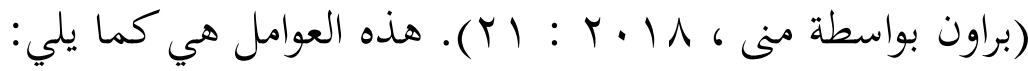

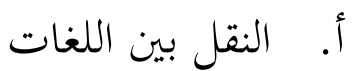

النقل بين اللغات هو سبب رئيسي لأخطاء اللغة لجميع المتعلمين ، لأنه في الأساس يعرف المتعلم اللغة الأولى لفترة أطول بكثير قبل معرفة لغة ثانية (لغة أجنبية) ، بحيث لا يعتادون على القواعد الجحديدة للغة الثانية وليسوا على دراية بها. ولا يزال الترتيب المستخدم يتأثر باللغة الأولى في الممارسة العملية باستخدام اللغة الجحديدة التي تعلموها.

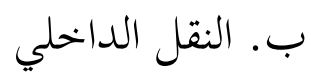
النقل الداخلي هو عامل رئيسي في خطاء تعلم لغة ثانية. وهذا العامل ناتج عن اللغة المستهدفة التي تعلمها متعلمو اللغة. ويحدث هذا الخطأ في بداية عملية التعلم. ج. سياق التعلم 
هذا العامل الثالث هو المصدر الرئيسي للأخطاء ، والأخطاء في سياق التعلم هي الأخطاء التي تحدث بسبب غياب المعلم في عملية التعلم ، بحيث يقوم المتعلمون بوضع الفرضيات الخاطئة في قواعد اللغة التي يتعلموها. إذا استمرت هذه الأخطاء بشكل مستمر ، فسوف يؤدي ذلك إلى إساءة فهم وتحدث أخطاء لغوية. د. استراتيجية الاتصال

ترتبط استراتيجية الاتصال هذه بأساليب التعلم. في نقل أفكارهم ، يستخدم المتعلمون استراتيجيات مختلفة لا يمكن قبول هذه الاستراتيجيات من قبل المحاورين ، مما يؤدي إلى سوء فهم مستمر. والغرض المقصود بين المتحدثين والمحاورين لديه استراتيجية مختلفة في التسليم.

\section{و. منهجية البحث}

ا.تم تضمين هذا البحث في فئة البحث النوعي الوصفي.

r.أجري هذا البحث في اب مارس 9 1.r - اب يوليو 9 ابr في حرم معهد دار السلام الإسلامي في بلوكاجونج.

r.البيانات الرئيسية في هذه الدراسة هي الأخطاء التي تحدث على نتائج ترجمة طلاب برنامج دراسة تعليم اللغة العربية التابع لمعهد دار السلام دار السلام الإسلامي في بلوكاجونج بانيوانغي في عام 7 ا ـ Y. 
ع. يتم جمع البيانات عن طريق إعطاء مقالات قصيرة للطلاب واطلب منهم ترجمتها إلى اللغة العربية. بعد الحصول على نتائج الترجمة ، حدد المؤلفون هذه النتائج. ه.الأسلوب الذي أستخدمه هو اتباع خطوات سوزان جاس ولاري سيلينكر

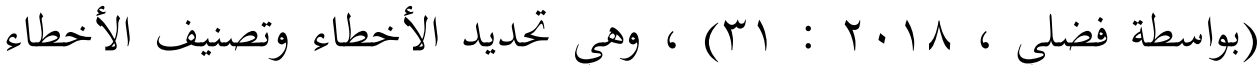
وحساب الأخطاء وتحليل أسباب الأخطاء وإصلاح الأخطاء.

وجد الباحث في نتائج ترجمة برنامج تعليم اللغة العربية لعام 17 • Y أخطاء في اختيار الكلمة على النحو التالي. الجحدول الأول : الأخطاء في اختيار الكلمة

\begin{tabular}{|c|c|c|c|c|}
\hline \multicolumn{2}{|c|}{ النص المستهدف } & \multirow{2}{*}{ النص المصدر } & \multirow{2}{*}{ رقم البيانات } & \multirow{2}{*}{ الرقم } \\
\hline التصحيح & الحخطأ & & & \\
\hline بحث المسائل & بحث المسائل & & & \\
\hline هو بحلس & هو مروفاكان & $\begin{array}{l}\text { Bahtsul masail adalah } \\
\text { merupakan forum }\end{array}$ & & \\
\hline المشاورة الدينية & مجلس المساورة & $\begin{array}{l}\text { diskusi keagamaan } \\
\text { yang sudah mendarah }\end{array}$ & $r$ & 1 \\
\hline الذي صار & الدينية الذي & daging di pesantren. & & \\
\hline طبيعة ثانوية في & خلاص دام & & & \\
\hline
\end{tabular}




\begin{tabular}{|l|l|l|l|l|}
\hline اللحمثم في المعهد & & & \\
\hline
\end{tabular}

الوصف: ليس اختيار القول "خلاص دام اللحم" في هذا البيان صحيحا.

وكان سبب خطأه بسبب الاختلاف بين المعنى الوارد في لغة المصدر ولغة الهدف.

وأما المعنى المطلوب في لغة المصدر في الجملة ”yang sudah mendarah daging

فهو الشيء الذي أصبح شخصية مسألة أخرى. وكان ترجمة الجملة لا تشير إلى المعنى

المطلوب للغة المصدر ، ولكن تعني معنا أصليا. والجملة المختارة المناسبة لترجمة

الجملة ”yang sudah mendarah daging " هي الجملة "صار طبيعة ثانوية". وهذه

الجملة أكثر ملاءمة لأها تحتوي على المعنى المطلوب من قبل لغة المصدر بحيث لا

يغير المعنى المطلوب للغة المصدر.

\section{ب. الأخطاء في حذف الكلمة}

\section{الجدول الثاني : الأخطاء في حذف الكلمة}

\begin{tabular}{|c|c|c|c|c|}
\hline \multicolumn{2}{|c|}{ النص المستهدف } & \multirow{2}{*}{ النص المصدر } & \multirow{2}{*}{ البيانات } & \multirow{2}{*}{ الرقم } \\
\hline التصحيح & الحطأ & & & \\
\hline وفيائ تبحثل البحتمع & المسائل بيتحتمع & $\begin{array}{c}\text { Didalamnya dibahas } \\
\text { persoalan-persoalan } \\
\text { masyarakat }\end{array}$ & Tr & 1 \\
\hline
\end{tabular}

الوصف: الخطأ في كلمة "يف" هو حذف اسم الضمير الذي يشير إلى كلمة

"بحث المسائل" في الفقرة السابقة. وكان "بحث المسائل" مفردا مذكرا. وفي هذه الجملة 
، يجب أن يكون هناك رابط بين الجملة في البيانات أعلاه والجملة السابقة. ويجب أن

$$
\text { يكتب المترجم "وفيه" بزيادة الضمير في محل الجر. }
$$

\section{ج. الأخطاء في زيادة الكلمة}

يتم تفسير أخطاء زيادة الكلمة عن طريق إضافة الكلمات أو الجمل التي

$$
\text { يمكن أن تغير المعنى أو لا وهي تفعل من قبل المترجم. }
$$

\begin{tabular}{|c|c|c|c|c|}
\hline \multicolumn{2}{|c|}{ النص المستهدف } & \multirow{2}{*}{ النص المصدر } & \multirow{2}{*}{ البيانات } & \multirow{2}{*}{ لرقم } \\
\hline النصحيح & الحُطأ & & & \\
\hline 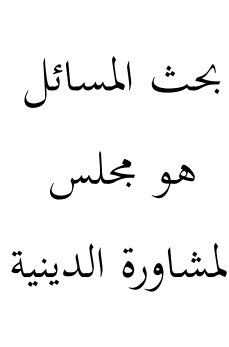 & بحو مجل مروفاكان المسائل & $\begin{array}{l}\text { Bahtsul masa il adalah } \\
\text { merupakan forum diskusi } \\
\text { keagamaan }\end{array}$ & 09 & $r$ \\
\hline
\end{tabular}

الجمدول الثالث : الأخطاء في زيادة الكلمة

الوصف: وجدت في البيان زيادة كلمة "مروفاكان" الإندونيسية ولكنها مكتوبة

باستخدام حروف الهجائي أو المعروفة باسم باستبدال حرفي أو يسمى في اللغة

الإندونيسية باسم فيكان (pegon) نظرًا لعدم وجود تغيير من لغة المصدر إلى لغة

$$
\text { الهدف ليس ذلك ترجمة. ولذلك يتم تضمين ذلك في شكل خاطئ. }
$$


لا ينبغي كتابتها لأهما ستغير المعنى أو الفهم المختلف عن الغرض من لغة

المصدر. وبالإضافة إلى ذلك ، ترجمة "merupakan" ممثلة بالفعل بحضور الضمير هو.

بحيث أن الجملة الدقيقة التي كتبها المترجم هي بحث المسائل هو بجلس المشاورة الدينية.

د. الأخطاء في القواعد النحوية

الجدول الرابع : الأخطاء في القواعد النحوية

\begin{tabular}{|c|c|c|c|c|}
\hline متهدف & النص ا & $10 \mathrm{dl}$ & رقم & \\
\hline التصحيح & الخطأ & & بيانات & \\
\hline وفيائ تبحث البمتمع & يبحث المسائل & $\begin{array}{l}\text { Didalamnya, dibahas } \\
\text { persoalan-persoalan } \\
\text { masyarakat }\end{array}$ & 77 & 1 \\
\hline
\end{tabular}

الوصف: حدث خطأ في كلمة "يبحث" خطأ في استخدام قاعدة الفاعل.

يترجم المترجم الفعل "يبحث" بالواقع المفرد المذكر مع أن فاعله أي كلمة "المسائل"

هي جمع التكسير غير العاقل. ويتم تضمين هذا الخطأ في خطأ القاعدة النحوية.

ويجب على المترجم كتابة كلمة "تبحث".

هـ. الأخطاء المورفولوجية 
الجحدول الخامس : الأخطاء المورفولوجية

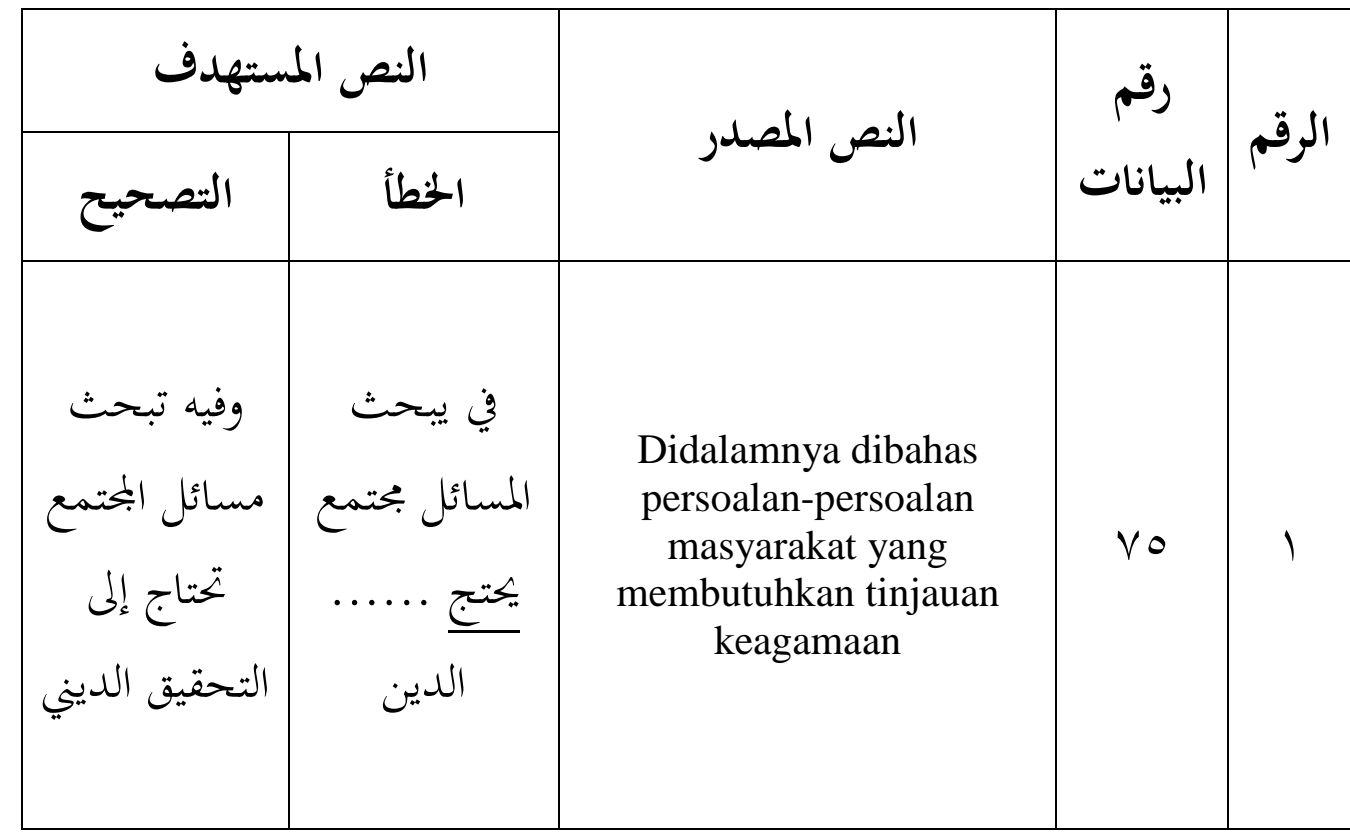

الوصف: وجد الخطأ في البيان ، وهو عدم الألف في كتابة كلمة "يحتج"

ترجمة كلمة ”membutuhkan" ، وكان بناء "يحتج" أجافا واويا. وينبغي للمترجم أن

يكتبه تحتاج بزيادة الألف.

$$
\text { r. (1أسباب الحطأ }
$$

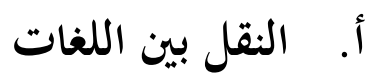

النقل بين اللغات خطأ من أخطاء لغوية ناتج عن تأثير اللغة الأولى على

متعلمي اللغة الثانية (لغة أجنبية). كانت لغة المصدر هي النظام الوحيد الذي يتحكم فيه المترجم. تحدث هذه التأثيرات في جميع الزوايا على مستوى أشكال وعناصر اللغة. بشكل عام ، تتأثر الأخطاء الناتحة عن العوامل البينية بعملية التعلم التي تقل عن الحدد الأقصى بحيث يكون لدى متعلمي اللغة أخطاء في الترجمة باستخدام اللغة الثانية 
(العربية). يمكننا أن نرى خطأ نابتا عن النقل بين اللغات في البيان (؟) ، وهو خطأ

الجمدول السادس : النقل بين اللغات

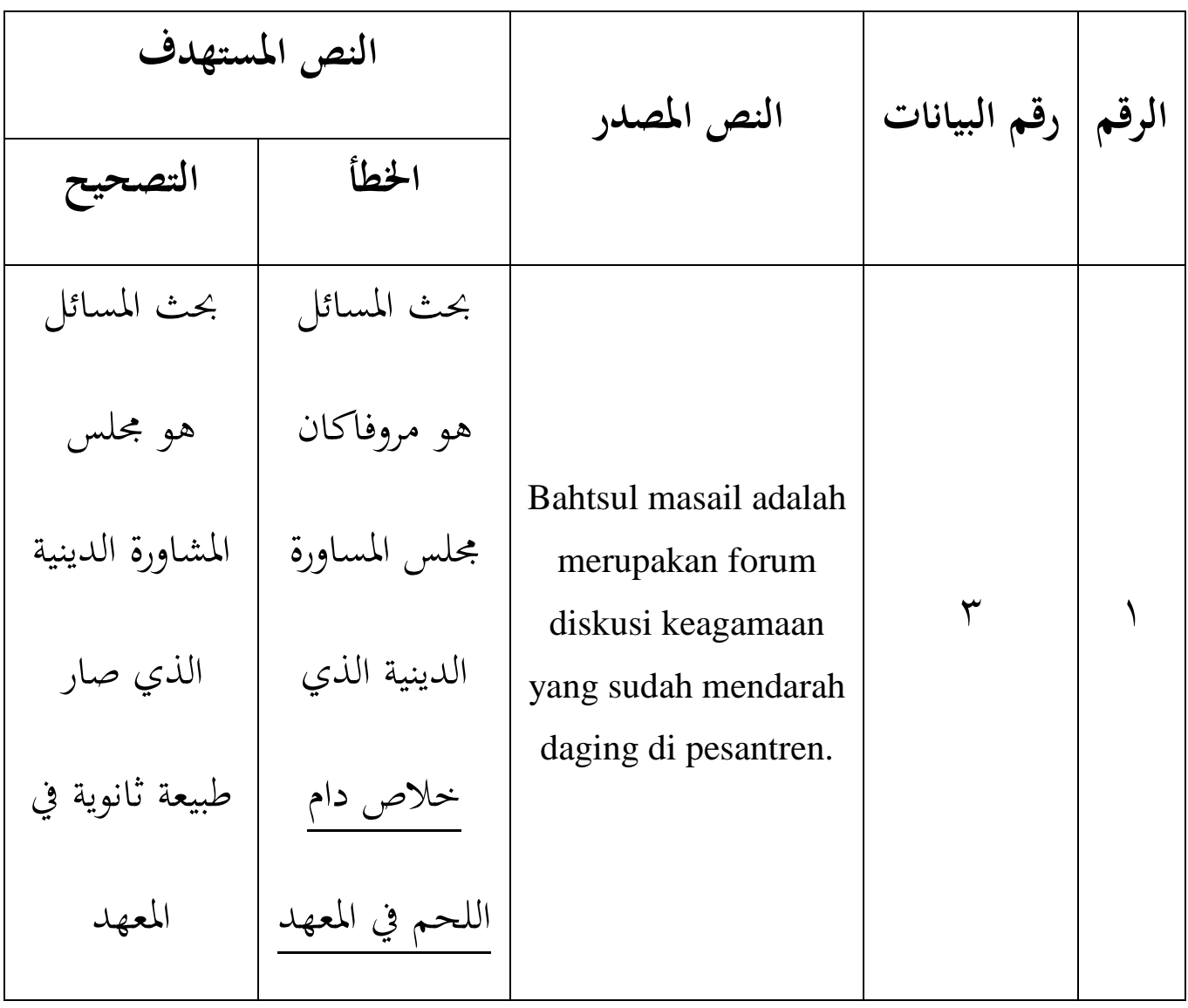

يُفترض أن كلمة خلاص دام اللحم في البيان (r) هي شكل من

أشكال خطأ اللغة الناجم عن النقل بين اللغات. حيث يقوم المترجم بترجمته

sudah " من اللغة الأولى إلى اللغة الثانية عن طريق النقل الحرفي لعبارة

mendarah daging "التي تستخدم عادة في اللغة الأولى أو لغة المصدر وأيضا

$$
\text { بسبب اختيار الكلمات غير صحيح. }
$$




\section{ح. خلاصة}

بعد أن أجرى البحث ، وحدد ، وصنف ، وحلل ، وصحح البيانات النصية

لنتائج ترجمة طلاب قسم تعليم اللغة العربية ، يمكن الحصول على الاستنتاجات على النحو التالي.

أشكال الأخطاء التي تحدث في ترجمة الطلاب هي الأخطاء في اختيار

الكلمات ، والأخطاء في حذف الكلمات ، والأخطاء في زيادة الكلمات ، والأخطاء

في القواعد النحوية ، والأخطاء في المورفولوجية.

وأما أسباب الأخطاء ، فهناك شيئان أساسان للأخطاء ، وهما النقل بين

اللغات والنقل داخل اللسان. يمكن رؤية الأخطاء اللغوية من عناصر اللغة المصدر

الموجودة في اللغة الهدف ، إما في شكل عناصر نوية معينة أو هياكل معينة. وفي

الوقت نفسه ، فإن الأخطاء النابحة عن عمليات النقل الداخلية هي أخطاء نابتحة عن

عدم فهم القواعد.

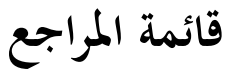

Akmaliyah. 2017. Teori dan Praktik Terjemah Indonesia-Arab. Depok: Kencana.

Al-Ghalayini, Moustafa. 2017. Jami Ad-Durus Al-Arabiyyah. Beirut: Dar AlKotob Al-Ilmiyah. 
Al-Khatib, Thahir Yusuf. tt. Al-Mu'jam Al-Mufashshal Fi Al-I'rab. Indonesia: AlHaramain.

Asror, Chozin. 2009. Analisis Kesalahan Menerjemahkan Bahasa Arab ke dalam Bahasa Indonesia Siswa Kelas X MAN Wonokromo Yogyakarta. Skripsi tidak diterbitkan. Yogyakarta: Fakultas Tarbiyah Universitas Islam Negeri Sunan Kalijaga.

Brown, H. Douglas. 2000. Principles of Language Learning and Teaching. Fourth Edition. San Fransisco: Addison Wesley Longman, Inc.

Chapakiya, Suraiya. 2014. Asas Linguistik. Kuala Lumpur: PTS Akademia.

Dulay, Heidi, Burt, Marina dan Krashen, Stephen. 1982. Language Two. New York: Oxford Univertsity Press.

Hidayatullah, Moch. Syarif. 2017. Jembatan Kata: Seluk-Beluk Penerjemahan Arab-Indonesia. Jakarta: Grasindo.

Ma'sum, Muhammad. tt. Al-Amtsilah Al-Tashrifiyyah. Surabaya: Maktabah AsSyaikh Salim Bin Sa'ad Nabhan.

Mufarih Hasan Fadly, Ahmad. 2018. Kesalahan Gramatika Bahasa Arab (Studi Kasus Tulisan Al-Ikhtishar Mahasiswa Sastra Arab UGM). 2(1): 31.

Mufid, Nur \& Kaserun AS. Rahman. 2007. Buku Pintar Menerjemah ArabIndonesia (Cara Paling Tepat, Mudah dan Kreatif). Surabaya: Pustaka Progressif.

Mufid, Nur. 2010. Kamus Modern Indonesia-Arab Al-Mufied. Surabaya: Pustaka Progressif. 